Article

\title{
The Influence of Urban Land-Use and Public Transport Facilities on Active Commuting in Wellington, New Zealand: Active Transport Forecasting Using the WILUTE Model
}

\author{
Joreintje Dingena Mackenbach ${ }^{1, *}$, Edward Randal ${ }^{2}$, Pengjun Zhao ${ }^{3}$ and \\ Philippa Howden-Chapman ${ }^{2}$ \\ 1 Department of Epidemiology and Biostatistics, EMGO Institute for Health and Care Research, \\ VU University Medical Center, Amsterdam 1081HV, The Netherlands \\ 2 NZ Centre for Sustainable Cities, University of Otago, Wellington 6242, New Zealand; \\ edward.randal@otago.ac.nz (E.R.); philippa.howden-chapman@otago.ac.nz (P.H.-C.) \\ 3 Department of Urban and Regional Planning, College of Urban and Environmental Sciences, \\ Peking University, Beijing 100871, China; pengjun.zhao@pku.edu.cn \\ * Correspondence: j.mackenbach@vumc.nl; Tel.: +31-204-448-198
}

Academic Editor: Tan Yigitcanlar

Received: 8 January 2016; Accepted: 2 March 2016; Published: 5 March 2016

\begin{abstract}
Physical activity has numerous physical and mental health benefits, and active commuting (walking or cycling to work) can help meet physical activity recommendations. This study investigated socioeconomic differences in active commuting, and assessed the impact of urban land-use and public transport policies on active commuting in the Wellington region in New Zealand. We combined data from the New Zealand Household Travel Survey and GIS data on land-use and public transport facilities with the Wellington Integrated Land-Use, Transportation and Environment (WILUTE) model, and forecasted changes in active commuter trips associated with changes in the built environment. Results indicated high income individuals were more likely to commute actively than individuals on low income. Several land-use and transportation factors were associated with active commuting and results from the modelling showed a potential increase in active commuting following an increase in bus frequency and parking fees. In conclusion, regional level policies stimulating environmental factors that directly or indirectly affect active commuting may be a promising strategy to increase population level physical activity. Access to, and frequency of, public transport in the neighbourhood can act as a facilitator for a more active lifestyle among its residents without negatively affecting disadvantaged groups.
\end{abstract}

Keywords: active commuting; transport policy; forecasting; built environment; physical activity

\section{Introduction}

Regular physical activity has been consistently associated with numerous physical and mental health benefits [1-4]. Physical inactivity is estimated to be the fourth leading cause of global mortality [5]. The promotion of sufficient levels of physical activity is therefore of utmost importance. One strategy for increasing population physical activity levels is to stimulate active commuter journeys (walking or cycling to work) [6]. Commuter journeys are a major share of the distance travelled by adults, and are a way in which physical activity could be built into the daily routine.

More than half (54\%) of New Zealand adults do not achieve the recommended physical activity levels $[7,8]$. Walking is the main mode of transport to and from work for $7 \%$ of adults, but only $3 \%$ cycle [9]. While walking to work is similar to the Dutch population (5\%) for example this is much lower than the percentage of Dutch people cycling (24\%) [10]. 
There is increased attention for the role of urban environments in the accumulation of physical activity through different modes of transport [11]. The provision of safe and continuous cycling facilities, in combination with strict land-use policies that foster compact, mixed-use developments (allowing for shorter and thus more bikeable trips), has been hypothesized to explain the success of cycling rates in the Netherlands [12]. Urban environmental features can play a direct role (via the presence of cycle paths or pedestrian crossings), or an indirect role (via better access to public transport and greater barriers for car driving) in stimulating active commuting [13-15]. Factors like housing density, walkability, land-use-mix, traffic-related factors, absence of steep inclines, presence and quality of cycling lanes, greenery and street connectivity have all been positively associated with active transport [11,16,17]. Although Nazelle et al. (2011) and Martin et al. (2012) concluded that urban transport policies provide the opportunity for an integrative approach to tackle physical activity, carbon emission and traffic congestions [13,18], policymakers often face the question as to whether policy interventions at a city or regional level efficiently promote active commuting [19].

Previous studies that examined associations between the built environment and active travel have a number of limitations. First, many studies focused on the built environment only within the residential neighbourhood [20]. However, especially for commuter trips, environmental characteristics at both the starting and finishing areas of the commuter trip may be important as well [21]. Further understanding of the influence of urban land-use and public transport facilities at journey origin and destination is thus warranted. As cross-sectional and quasi-experimental studies often give limited insights in the effect of changes in the built environment over time, they do not allow for the exploration of different policy scenarios. Forecasting models allow for more insight into the consequences of changing certain urban characteristics, without exposing individuals to a potentially adverse environment or having to invest in major urban environmental changes. Examples of such models are the Leeds Integrated Land-Use/Transport model (LILT), the California Urban Futures Model (CUFM) and the Integrated Transportation and Land Use Package (ITLUP) [22]. The effects of land-use and transport policies can be considered using specific policy scenarios, and the outcomes generated can assist in evaluating different policy options.

Yet, when considering changes in land-use and active transport facilities, it is important to assess the potential differential effects on people from different socioeconomic groups, so as not to increase inequalities (at the expense of the most disadvantaged) in the environmental determinants of health. Existing studies on socioeconomic inequalities in active transport provide inconsistent results [23]. For example, a Dutch study suggests that more educated adults are more likely to actively commute [24], whereas studies from the UK and Australia show the reverse [25-27]. It remains unclear whether the urban design of the areas people live in contribute to such inequalities.

The Greater Wellington region in New Zealand aims to develop and promote active transport facilities and infrastructure [28]. The Wellington city centre already has the highest active travel mode share in New Zealand [9], but aims to further increase active modes during the coming decades [28]. We examined whether changes in land-use and public transport facilities have the potential to increase active commuter trips by exploring alternative policy scenarios modelled in the Wellington Integrated Land-Use Transportation and Environment Model (WILUTE) system model. The objective of the present study is threefold, to: (i) examine socioeconomic differences in active commuting; (ii) assess environmental correlates of active commuting; and (iii) model the impact of different urban policy scenarios on active commuting.

\section{Materials and Methods}

The approach for this study consisted of three steps that correspond to the three objectives of the study. Firstly, we examined socioeconomic differences in active commuting using cross-sectional, observational data from the New Zealand Household Travel Survey (NZHTS). Secondly, we combined this data with geographic information systems (GIS) data on built environmental (land-use and transport) variables to examine the association between several built environmental variables and 
active commuting. Thirdly, we examined the impact of built environment policy scenarios on active commuting (such that they would not disadvantage low income commuters) using the Wellington Integrated Land-Use Transportation and Environment Model (WILUTE) system model.

\subsection{Study Area and Sample}

We used data on adults from the ongoing NZHTS who participated in the 2008-2010 waves. The NZHTS is described in detail elsewhere [29]. Briefly, participating households were chosen from randomly selected meshblocks (neighbourhoods), with about a hundred households per meshblock. The meshblocks were sampled with probability proportional to size. Over a five-to-seven year cycle, every household in the selected neighbourhood will have been invited to participate in the survey. Following a letter from the Ministry of Transport, households were contacted by an interviewer who explained the procedures to the household members. Participants were asked to report different journeys made throughout the (randomly allocated) two consecutive diary-days. After the two "travel days", the interviewer conducted a household and personal interview with members of the household to record information on individual travel and demographics. Participants reported on sex, age, household type (living alone; adults living together as family; household with children; non-family adults) and income per week or year (based on 10 categories, ranging from 1 to 10,000 NZD per year to over 100,000 NZD per year) in the NZHTS personal questionnaire. Income was used as indicator of socioeconomic status [30]. When participants did not provide information on income (in approximately $10 \%$ of the cases), the Census-derived median income of the meshblock was used. Response rates within the NZHTS generally varied from $60 \%$ to $75 \%$. Sampling weights were calculated using SAS, accounting for potential selection bias arisen in the two-stage stratified sampling. More information on the survey methods and weighting is available online [29] As the WILUTE model comprises the western part of the Greater Wellington region, all analyses were restricted to NZHTS respondents (aged 20-65 years) living in this area and commuting to work $(N=482)$.

\subsection{Outcome Variable-Active Commuting}

Active commuter trips as measured in the NZHTS were the unit of outcome. Active commuting was defined as walking or cycling to work. A journey from home to work could consist of different trip legs. For example: the participant walks from home to the bus stop (trip leg 1); waits at the bus stop; takes the bus (trip leg 2); and then walks from the bus stop to the workplace (trip leg 3). Walking trip legs were included if the route was longer than 100 meters or crossed a road and for which the purpose was "work". As we only had information on trips from home to work, we assumed that the travel mode for the journey to work would be mirrored in the journey back. Active commuter trips were defined as trips with an active mode that had a duration of at least ten minutes (following the definition by Kerr et al. [31]). As this would equate an active trip of $10 \mathrm{~min}$ to an active trip of $40 \mathrm{~min}$, we additionally used the total duration (in minutes) of the active component of commuter trips during the two-day survey period as a second outcome variable. Commuters who did not travel by foot or bicycle were included in this analysis with value zero for trip duration.

\subsection{Exposure Variables—Built Environment Variables}

For each participant of the NZHTS, information on the location of their home area (at the meshblock level), and the location of the start and end of their journey to work (at the traffic zone level-which can contain 20 meshblocks) were available. This allowed for the exploration of the influence of urban land-use and public transport facilities at journey origin and destination, as well as in the residential neighbourhood. Trip distances for cycle and motor vehicle trips were calculated from the origin and destination addresses provided by the respondents.

Land-use and transport facility measures (from 2006) were derived using a geographic information system (ArcGIS 10, ESRI) [32]. Data on population-, housing- and apartment density, job accessibility (presence and intensity of workplaces) as well as on land use mix (the number of mixed-use buildings 
per hectare of useable land) were provided by Quotable Value (Wellington, New Zealand) (a state owned enterprise in New Zealand, see https://www.qv.co.nz/). Data on public transportation were provided by the Greater Wellington Regional Council. Information on on-street parking prices were provided by the Wellington region local authorities. We used the 2006 NZ Deprivation score [33] as an indication of area deprivation. Information on walkability and transit scores were derived by manually scoring at least five streets, and averaging these scores, within each meshblock using www.walkscore.com. Not all variables were available in the home meshblock as well as in the start and end traffic zones. Variables and their availability across different geographic units are described in Table 1 and summary statistics are shown in Table S1. Information on transport variables was derived from the Greater Wellington Regional Council.

\subsection{Data Analysis}

\subsubsection{Regression Analysis}

Firstly, we explored the socioeconomic differences of active commuting with mixed multilevel logistic regression analyses. This type of analysis allows for the non-independence of observations within meshblocks [34]. We used odds of active commuting for at least ten minutes as a dependent variable, and income levels as independent variable. Models were adjusted for age, sex, household type, season and day of the week. As sensitivity analysis, we repeated the analyses with household income as a continuous variable, and used duration of the active component of commuter trips as an outcome.

Secondly, we initially assessed correlations between built environmental (land-use and transport) variables to investigate the interrelation of built environmental variables. To assess the impact of land-use and transport variables on likelihood of active commuter trips, we performed logistic regression analysis with repeated measures. In light of the strong correlations between the land-use and transport variables, each of the area exposures was modelled separately. We transformed a number of exposure variables to satisfy assumption of normality, namely apartment density, bus frequency, job accessibility and mixed land-use. We distinguished between exposure variables in home meshblock, the starting traffic zone and the end traffic zone. Models were adjusted for income, age, sex, household type, season, day of the week and trip distance. As sensitivity analysis, we repeated the analyses with duration of the active component of commuter trips as an outcome using linear regression analysis with repeated measures. Geographic maps were created to visually support the findings from the regression analyses using ArcGIS.

To evaluate whether the association between built environmental variables and active commuting was similar for individuals with high and low incomes, we tested for statistical interaction between income and environmental variables as part of the regression analysis. As a sensitivity analysis, we repeated the analyses with trips with a distance less than 15 kilometers only, and trips with a distance less than 20 kilometers only. As Ewing and Cervero (and Witten et al. specifically for the New Zealand context [17]) showed that residential self-selection had virtually no effect on the association between built environmental factors and walking for transport [35], we did not take this into account in the present analysis.

All regression analyses with repeated measures were conducted using STATA version 12.1 [36]. 
Table 1. Data sources and GIS method used in calculating exposure measures.

\begin{tabular}{|c|c|c|c|c|c|c|}
\hline Measure & Data Source & Year & Definition & $\begin{array}{c}\text { Available for } \\
\text { Home Meshblock }\end{array}$ & $\begin{array}{c}\text { Available for } \\
\text { Start Trafficzone }\end{array}$ & $\begin{array}{l}\text { AvaiLable for } \\
\text { End Trafficzone }\end{array}$ \\
\hline population density & Census \& Quotable Value & 2006 & number of persons per hectare of useable land & $\mathrm{x}$ & $\mathrm{x}$ & $\mathrm{x}$ \\
\hline housing density & Quotable Value & 2006 & number of houses per hectare of useable land & $\mathrm{x}$ & $\mathrm{x}$ & $\mathrm{x}$ \\
\hline apartment density & Quotable Value & 2006 & number of apartments per hectare of useable land & $\mathrm{x}$ & $\mathrm{x}$ & $\mathrm{x}$ \\
\hline land use mix & Quotable Value & 2006 & number of mixed-use buildings per hectare of useable land & $\mathrm{x}$ & $\mathrm{x}$ & $\mathrm{x}$ \\
\hline distance to $\mathrm{CBD}$ * & $\begin{array}{l}\text { Greater Wellington } \\
\text { Regional Council }\end{array}$ & 2006 & $\begin{array}{l}\text { road distance from the home census area unit (CUA) } \\
\text { centroid to the Wellington Business District CUA centroid. }\end{array}$ & $\mathrm{x}$ & & \\
\hline frequency bus & $\begin{array}{l}\text { Greater Wellington } \\
\text { Regional Council }\end{array}$ & 2006 & $\begin{array}{l}\text { number of buses crossing the bus route(s) in the area } \\
\text { per day }\end{array}$ & $\mathrm{x}$ & $\mathrm{x}$ & $\mathrm{x}$ \\
\hline number of bus stops & $\begin{array}{l}\text { Greater Wellington } \\
\text { Regional Council }\end{array}$ & 2006 & number of pairs of bus stops in the area & $\mathrm{x}$ & $\mathrm{x}$ & $\mathrm{x}$ \\
\hline frequency train & $\begin{array}{l}\text { Greater Wellington } \\
\text { Regional Council }\end{array}$ & 2006 & $\begin{array}{l}\text { number of trains crossing the rail-way line(s) in the area } \\
\text { per day }\end{array}$ & $x^{\#}$ & $\mathrm{x}$ & $\mathrm{x}$ \\
\hline $\begin{array}{l}\text { number rail-way } \\
\text { stations }\end{array}$ & $\begin{array}{l}\text { Greater Wellington } \\
\text { Regional Council }\end{array}$ & 2006 & number of rail stations in the area & $x^{\#}$ & $\mathrm{x}$ & $\mathrm{x}$ \\
\hline job accessibility & Quotable Value & 2006 & $\begin{array}{l}\text { a score for the presence or absence, or an intensity measure } \\
\text { of workplaces accessible within walking distance }(800 \mathrm{~m} \\
\text { along street network) of an area centroid }\end{array}$ & & $\mathrm{x}$ & $\mathrm{x}$ \\
\hline material deprivation & Census NZDep & 2006 & $\begin{array}{l}\text { a score from } 1 \text { (least deprived) to } 10 \text { (most deprived) on the } \\
\text { basis of } 9 \text { deprivation characteristics }\end{array}$ & $\mathrm{x}$ & & \\
\hline parking price & Local Authorities & 2011 & the price of commuter on-street parking per hour & & & $x^{\$}$ \\
\hline walkability & www.walkscore.com & 2013 & a walkability score based on distance to nearby facilities & $\mathrm{x}$ & & \\
\hline transit score & www.walkscore.com & 2013 & a score for useful public transport routes & $\mathrm{x}$ & & \\
\hline
\end{tabular}

${ }^{*}$ CBD $=$ Central Business District; ${ }^{\#}$ First inspection of the data revealed that none of the home meshblocks of participants of the 2008-2010 HTS contained rail stations. Therefore, analysis was only conducted with number of train stations (and frequency of trains) in the start and end traffic zones; ${ }^{\$}$ Parking is free in most residential areas, so we only assessed the price of parking in the traffic zones where trips ended. 


\subsubsection{Scenario Modelling}

Thirdly, we used the WILUTE model in combination with data from the NZHTS to forecast the impact of built environment policy scenarios on active commuting. The development and operation of the WILUTE model has been described elsewhere [37]. Briefly, the WILUTE model integrates six sub-models (e.g., a land market model, a growth distribution model and a four-step transport model) in a transparent system, while land-use and transport choices are simulated using a discrete choice approach, based on utility theory, allowing relatively detailed modelling of individuals' behaviour. In this study, we used the "trip generation model". The model allows for modelling different policy and land-use scenarios and assessing their influence on individual active commuting.

We compared a "business as usual scenario" (based on predicted populations changes between 2006 and 2031) with an "alternative scenario". The "business as usual" scenario is essentially a prediction model for future trips made in the Wellington region. WILUTE was used to estimate the average daily number of trips (by all modes) made by each age group for each trip purpose in 2031 (a 25-year period from 2006). In this study we focused on commuter trips by adults only. Firstly, the predicted populations for 2031 for each traffic zone were calculated using subnational population projections from Statistics New Zealand. It was assumed that the proportion of working age adults would remain constant, and that the regional population growth will be spread proportionally across traffic zones based on 2006 populations. These predicted populations were used to adjust variables directly affected by population change such as the number of houses and apartments and population density in each traffic zone. We assumed that the land area per house or apartment, as well as the land area per person for commercial, industrial, public and mixed use properties would remain the same as in 2006. Additionally, we made the assumption that the average household size would stay the same (New Zealand average household size of 2.6 people). The trip generation regression model of WILUTE uses these calculated variables to give projected average daily numbers of trips generated from each traffic zone by each person category for each trip type in 2031. On the basis of these predictions we determined the proportion of trips that would be made by active modes.

In the "alternative scenario", we used variables that were significantly associated with active commuting to calculate probabilities of commuter trips in 2031 being active commuter trips. Coefficients from the regression analysis in the second step were used to generate $\beta$ coefficients. Based on mean values for each traffic zone in 2006, we calculated projections of how trip numbers would change as a result of changes in any of the land use and transport variables in the end traffic zones. We focused on variables that would require relatively few structural changes in the built environment and would not have differential effects on high and low income individuals according to results from the previous analysis in order to prevent a widening in socioeconomic inequities in active commuting.

In the WILUTE model, populations were categorized according to age group (0-9 years; 10-19 years; 20-64 years-no or low income; 20-64 years, mid-high income; age 65+ years), journey purpose (home, work, recreation etc.) and travel mode (car, bicycle, on foot etc.). For this study, only journeys to work in groups 3 and 4 (adults) were included in the analysis with the WILUTE model.

The trip generation model in WILUTE was cross-validated with 2012 NZHTS and census data. The trip generation model with 2006 data was used to predict trips in 2012 and these predictions were compared to the observed 2012 NZHTS trip data. The model only had small errors: the mean absolute percentage error was $-1.50 \%$ for category 3 (adults with low income) and $0.12 \%$ for category 4 (adults with medium or high income).

\section{Results}

Sociodemographic characteristics of the 481 participants are described in Table 2. Fifty-three percent of commuters were men, the mean age was 42.34 years $(\mathrm{sd}=11.64)$ and $28.7 \%$ received a low yearly income. Of the 1806 commuter trips, 592 were active commuter trips (32\%, of which 12 were cycling commuter trips). Of the 582 active commuter trips, $34 \%$ were part of a multi-modal trip and 
$66 \%$ were active only. The average duration of an active trip was $9.9 \mathrm{~min}(\mathrm{sd}=1.1)$, and the average distance travelled was 1.0 kilometers $(\mathrm{sd}=0.1)$. The cycling trips were removed from further analyses as they only made up a very small proportion of the active commuter trips.

Table 2. Characteristics of 481 NZHTS commuters between 2008 and 2010.

\begin{tabular}{lc}
\hline \multicolumn{1}{c}{ Variable } & $\boldsymbol{n} \mathbf{( \% ) / M e a n} \pm$ SD \\
\hline Age (years) & $42.3 \pm 11.6$ \\
Sex & \\
$\quad$ male & $256(53.2 \%)$ \\
female & $225(46.8 \%)$ \\
Household type & \\
with children & $227(47.1 \%)$ \\
single household & $34(7.1 \%)$ \\
adult family members & $191(39.6 \%)$ \\
non-family adults & $30(6.2 \%)$ \\
Income & \\
low (<30,000 NZ\$ per year) & $138(28.7 \%)$ \\
medium (30,001-70,000 NZ\$ per year) & $219(45.5 \%)$ \\
high (>70,001 NZ\$ per year) & $124(25.8 \%)$ \\
Ethnicity & \\
European & $380(79 \%)$ \\
Māori & $35(7.3 \%)$ \\
Pacific & $13(2.7 \%)$ \\
Asian & $47(9.8 \%)$ \\
Other & $6(1.2 \%)$ \\
\hline
\end{tabular}

Firstly, we examined socioeconomic differences in active commuting. Table 3 shows participants with low and medium incomes had a significantly lower likelihood of active commuting than people on high incomes. Analysis using duration of active trips as outcome (Table S2) suggests that individuals on medium and low incomes made shorter active commuter trips, although coefficients were not significant.

Table 3. Association between level of income and likelihood of active commuting.

\begin{tabular}{|c|c|c|c|c|}
\hline Model & Independent Variables & OR (95\% CI) & $p$-Value & $\mathbf{N}$ \\
\hline Model 1 & $\begin{array}{l}\text { high income (ref.) } \\
\text { medium income } \\
\text { low income }\end{array}$ & $\begin{array}{c}1 \\
0.62(0.47,0.82) \\
0.58(0.41,0.81)\end{array}$ & $\begin{array}{l}0.001 \\
0.001\end{array}$ & 1794 \\
\hline Model 2 & $\begin{array}{l}\text { high income (ref.) } \\
\text { medium income } \\
\text { low income }\end{array}$ & $\begin{array}{c}1 \\
0.68(0.51,0.90) \\
0.55(0.39,0.77)\end{array}$ & $\begin{array}{l}0.006 \\
0.001\end{array}$ & 1794 \\
\hline Model 3 & income (continuous) & $1.09(1.04,1.15)$ & $<0.001$ & 1794 \\
\hline
\end{tabular}

\begin{abstract}
Notes: Active commuting was defined as a walking trip to work of at least 10 min of duration. Model 1 is an unadjusted model. Model 2 included the following covariates: age; sex (male (reference group), female); household income (low, medium, high (reference group)); household type (with children (reference group), alone, with adult family members, with non-family adults). In model 3 , income is analyzed as a continuous variable and adjusted for all covariates.
\end{abstract}

Secondly, we examined the association between built environmental (land-use and transport) variables and active commuting. We observed reasonably high correlations between the neighbourhood-level measures (Table S3), most notably between housing, apartment and population density. More deprived neighbourhoods tended to have higher population density and higher apartment density, but also had higher walkability and higher transit scores. Areas further away 
from the Wellington Central Business District (WCBD) had lower population, housing and apartment density, higher deprivation and lower walkability and transit scores. This finding is supported by the maps in Figure S1.

Focusing on the fully adjusted models, Table 4 shows that a higher housing density, higher walkability and higher transit score in the home area were significantly associated with higher likelihood of active commuter trips of people living in these areas. For example, a one point higher walk- or transit score (on a scale from 0 to 100) was associated with a $2 \%$ higher likelihood of active commuting. A higher housing density in the area where people started their commuter trip was significantly associated with a lower likelihood of active commuting. A higher parking price, higher number of rail stations, higher land-use mix, higher job accessibility and higher bus frequency-but lower bus stops and lower housing density-in the area where people ended their commuter trips (at work), were significantly associated with higher likelihood of active commuting. We found evidence for interaction between level of income and a number of built environment variables. Only the association of active commuting with land-use mix, bus frequency, job accessibility and parking price was similar in high and low income groups. Walkability, transit scores, population density, housing density and apartment density in the home area were positively related to active commuting in low income individuals, and not in high income individuals. Number of bus stops and train frequency was negatively related to active commuting in low income individuals, and not in high income individuals. For example, a higher transit score was associated with a higher odds of active commuting $(\mathrm{OR}=1.07, p<0.001)$ in low income individuals and not in high income individuals $(\mathrm{OR}=1.01, \mathrm{~ns})$.

Table 4. Likelihood (ORs, (95\% CIs)) of active commuting for each neighbourhood exposure.

\begin{tabular}{cccc}
\hline Neighbourhood Exposure & Home Meshblock & Start Traffic Zone & End Traffic Zone \\
\hline Adjusted for sociodemographics and trip distance & $n=1794$ & $n=1562$ & $n=1562$ \\
Population density & $1.00(1.00,1.01)$ & $\mathbf{0 . 9 9}(0.99,1.00)$ & $1.02(0.99,1.06)$ \\
Housing density & $\mathbf{1 . 0 9}(1.02,1.16)$ & $\mathbf{0 . 8 6}(0.77,0.96)$ & $\mathbf{0 . 8 2}(0.70,0.96)$ \\
Apartment density & $0.62(0.11,3.44)$ & $1.63(0.61,4.38)$ & $1.46(0.51,4.20)$ \\
Land use mix & $0.94(0.70,1.27)$ & $\mathbf{1 . 0 1}(1.00,1.02)$ & $\mathbf{1 . 0 1}(1.00,1.02)$ \\
Number of bus stops & $0.44(0.08,2.36)$ & $0.08(0.00,2.85)$ & $0.22(0.01,5.26)$ \\
Bus frequency & $1.00(0.99,1.03)$ & $0.99(0.99,1.00)$ & $\mathbf{1 . 0 2}(1.02,1.02)$ \\
Number of rail stations & & $1.51(0.97,2.32)$ & $\mathbf{1 . 7 1}(1.06,2.76)$ \\
Train frequency & & $0.99(0.99,1.00)$ & $0.99(0.99,1.00)$ \\
Job accessibility & & $\mathbf{1 . 1 1}(1.06,1.17)$ & $\mathbf{1 . 0 9}(1.04,1.15)$ \\
Parking price & & & $\mathbf{4 . 2 5}(2.79,6.45)$ \\
Medium deprivation & $0.82(0.36,1.86)$ & & \\
High deprivation & $1.04(0.50,2.16)$ & & \\
Walkability & $\mathbf{1 . 0 2}(1.01,1.03)$ & & \\
Transit score & $\mathbf{1 . 0 2}(1.01,1.04)$ & & \\
\hline
\end{tabular}

Notes: Bold values represent statistically significant ORs at the 0.05 level. Active commuting was defined as a walking trip to work of at least $10 \mathrm{~min}$ of duration. Estimates were generated using logistic regression models with repeated measures with the following covariates: age; sex (male (reference group), female); household income (low, medium, high (reference group)); household type (with children (reference group), alone, with adult family members, with non-family adults); trip distance. Walkability and transit score were not adjusted for trip distance, due to high collinearity.

We repeated analyses with trips with a distance of less than 20 and less than 15 kilometers, and results were essentially unchanged. Table S4 shows that higher land-use mix in the home area was significantly associated with a longer duration of active commuter trips. A higher number of bus stops in the home area was significantly associated with a shorter duration of active commuter trips of people living in these areas.

Finally, we examined the impact of built environment policy scenarios on active commuting. We generated two scenarios on the basis of the results in Table 4 . We calculated the probability that any trip in 2031 would be an active trip in a "business as usual" scenario compared with the probability in an alternative scenario. The probability was based on the seven statistically significant variables in the "end traffic zone" model from the second step. These were: housing density ( $\beta=-0.198)$, land-use 
$\operatorname{mix}(\beta=0.010)$, number of bus stops $(\beta=-9.2210)$, bus frequency $(\beta=0.020)$, number of rail stations ( $\beta=0.536)$, job accessibility $(\beta=0.086)$ and parking price $(\beta=1.447)$.

If business in 2031 were similar to business in 2006 (business as usual), the probability of a commuter trip being an active trip would be $19.7 \%$. This result is based on projected population growth during this period, and the associated changes in variables directly associated by population changes (such as housing density). Following the business-as-usual scenario, fewer active commuter trips would be conducted in 2031 than in 2006. In the alternative scenario, we decided to focus on two variables that were significantly related to active commuting, would require relatively few structural changes in the built environment, and did not have differential effects on high- and low income individuals: increasing parking price of on-street parking, and increasing bus frequency in the region. The number of rail stations (but not train frequency) in the destination area was also associated with an increased likelihood of active commuting, but building new rail stations would require a relatively large investment in supporting infrastructure (i.e., rails). We hypothesized a $20 \%$ increase of bus frequency and in meshblocks where there was free on-street parking in 2006, we hypothesized this would shift to paid parking with a price of NZD0.60 per hour (the minimum on-street parking price in 2006). (As paid parking was only implemented in 12 out of 185 traffic zones in 2006, changing the parking fees in those traffic zones (for example by $20 \%$ ) did not affect the estimation of the forecasted proportion of active commuter trips.)

Keeping all other factors constant, a $20 \%$ increase in bus frequency per day would result in $20.6 \%$ of commuter trips being active. Compared to the $19.7 \%$ in the business as usual scenario, this is an increase of $4.5 \%$. An increase in paid parking areas-keeping all other factors constant-would result in a percentage of $35.6 \%$ of commuter trips being active, an increase of $80 \%$. Increasing both bus frequency and paid parking would lead to a probability of $36.9 \%$ of all commuter trips being active.

\section{Discussion}

This study examined the independent associations of land-use and public transport facilities-both in the home and the commuter trip environment-with active commuting, and assessed socioeconomic differences in active commuting. In contrast with previous studies [25,26,38], we showed that people on lower incomes conducted less active commuting and generally made active commuter trips of shorter duration. The Wellington region has previously been described as a regional outlier with regard to the relation between income and active commuting [39]. It could be that the particular geographic composition of the Wellington region leads to these findings, in the way that some of the areas where socioeconomically deprived residents live are so sprawling that active commuting is more difficult. As such, higher incomes in the Wellington region allow for shorter commutes and the integration of active modes with public transport [39]. This emphasizes the importance of spatial context in research on socioeconomic inequities in active commuting [39].

Only a very small proportion of active commuter trips were cycling trips, so we focused on walking trips to work only. Several aspects of the neighbourhood built environment and transport facilities were associated with residents' likelihood of active commuting by facilitating or inhibiting active commuting. In line with a recent Australian study [21], both the areas where trips started and ended were of importance for active commuting. As shown in a systematic review by Saelens and Handy [40], and more recently the study by Kerr et al. [31], walking for transport to work was positively related to land-use mix. An additional positive association was found with housing density (as shown by i.e., [41,42]), but only in the home area. The fact that analysis with home area generated different results than analysis with areas of the start and end of commuter trips may have several explanations. On the one hand, it may suggests that different mechanisms play a role. Although decisions to commute actively are made at the start of the trip, naturally they are not independent of the area where the trip ends, and the area where people reside. In the home area, a dense neighbourhood with good walking routes and good accessibility to transit can "push" adults into active commuting, while in the destination area, a combination of different transit options and job accessibility can "pull" 
(attract) adults into active commuting and away from taking the car. On the other hand, this finding may suggest that the choice of geographical unit level is of importance. Density in the home area was measured at the meshblock level, while density in the start and end traffic zone was measured at the traffic zone level, which is considerably larger. A previous study demonstrated that while compactness (density) at the county level was associated with walking, density at the metropolitan level was not associated with walking [43]. It might be that a dense, residential meshblock provides a proxy for the opportunity for individuals to walk to nearby facilities via a dense network of footpaths, while a high residential density at the traffic zone level may represent a lack of land-use mix.

Results from the logistic regression analysis also indicated that parking price and bus frequency were two important public transport variables related to active commuting. As building new rail stations requires a relatively large change of the urban form and infrastructure, and may decrease active commuting in low income adults, we decided to focus only on parking price and bus frequency. Although few natural experiments have been conducted, several observational studies have described that individuals travelling with public transport are considerably more likely to meet the weekly physical activity recommendations $[15,44,45]$. Another study showed that although changes in relative parking fees have little effect on mode choice (also shown by Feeney [46], individuals are relatively responsive to a change from "no" to "some" parking costs [47]. However, the effects of increased parking fees are dependent on parking demand, time of the day, possibilities for alternative transport modes and much more. As paid parking is generally only accepted in dense areas (although often parkers do not pay), pricing is not seen as the best means of stimulating the use of public and active transport. Instead, improvements in public transport facilities are seen as most preferred and most effective [48]. On the other hand, changing one environmental feature is not likely to shift population physical activity levels and a fixed parking price increase alone would have a greater impact on low income people. Therefore, focusing on an urban development that integrates increased public transport services with more accessible destinations, in combination with increased parking fees may favor active commuting. Moreover, decreased car use and increased public transport use could have additional effects, such as more compact, people-oriented urban design and increased road flow efficiency.

One of the novel aspects of this study pertains to the insight into where commuter trips actually took place. While previous studies examining effects of land-use on active transport were uncertain of built environments individuals were exposed to, we had information on the home area and areas of the start and the end of the trips (although the large traffic zones provided a relatively crude measure of exposure). Further, the use of a forecasting model allowed for the exploration of a scenario that involved changes in parking price and bus frequency, without exposing individuals to these changes or having to invest in such changes in the built environment. Although in reality, several factors change at the same time, specifically testing for the effect of changing a single factor while keeping all other factors fixed is an advantage of forecasting models that provides useful insight into the potential gains of specific environmental interventions. In the future, using smaller spatial scales (e.g., by applying microsimulation) will allow for the modelling of complex travel behaviours by taking into account individual-level interdependencies [22]. This may generate even more realistic scenarios. According to a review showing that many transportation policies have an inequitable impact on the travel behaviours in different socioeconomic groups [49], we also took into account the potential adverse effects of changes in land-use and public transport facilities on low income groups by studying socioeconomic differences in active commuting, and interactions between built environment and income level.

Despite the innovative approach in this study, we have to acknowledge a number of limitations of this study. This study was conducted in a specific region of New Zealand among a relatively small (although randomly selected) sample, and the model was built on the specific characteristics of the Wellington region at baseline (in 2006). As such, investments in train frequency or other public transport facilities that are currently not present in the Wellington region (e.g., light rail), may prove to positively impact active commuting in other regions. 
Further, the reliability of the results presented is subject to the validity of the model, the validity of the data, and the validity of the assumptions made. We used cross-sectional data from 2006 as input for the forecasting. By the time of publication, the data was nearly ten years old, and the built environment or demographic composition of the population may have been changed. On the other hand, using data from 2006 allowed us to validate the trip generation part of the model using actual data from the NZHTS from 2012 and comparing this to the estimated trips in 2012 based on the model. This showed that the model only had small errors: the mean absolute percentage error was $-1.50 \%$ for category 3 (adults with low income) and $0.12 \%$ for category 4 (adults with medium or high income). Still, using cross-sectional data as a basis for forecasting may have resulted in an overestimation of the effect. As such, the findings should be interpreted with caution.

Then, we have to acknowledge some limitations with regard to exposure to the built environment. For each participant of the NZHTS, information on the location of their home area (at the meshblock level), and the location of the start and end of their journey to work (at the traffic zone level—which can contain 20 meshblocks) was available. This allowed for the exploration of the influence of urban land-use and public transport facilities at journey origin and destination, as well as in the residential neighbourhood. Yet, the use of two different level of geographical units provided contradicting results, and there is a remaining uncertainty about true "exposure" when only taking into account administratively defined area boundaries [50].

With regard to our outcome measure; we conducted analyses with odds of "any active commuting", in which active commuter trips were defined as walking to work with a duration of at least ten minutes. Although we aimed to study active commuter trips, we removed cycling trips to work as they made up only a small proportion of the active commuter trips. Using this dichotomous outcome variable did not allow for a distinction between active trips with, for example, a duration of $10 \mathrm{~min}$ versus $45 \mathrm{~min}$. As the duration of an active trip is also important in assessing the potential for active commuting to increase physical activity levels, we additionally conducted analyses with "duration of active commuter trips" as outcome variable. These analyses showed that land-use and public transport facilities were not significantly associated with duration of active commuter trips. This may suggest that changes in urban land use and public transport may persuade non-active commuters to commute actively, but may not extend the duration of active commuter trips of those who already commute actively.

Lastly, we need to acknowledge that many environmental factors were interrelated, and that some of the more "favorable" factors (higher job accessibility, housing density, land-use mix and transit options) clustered around the WCBD. This corresponds to the notion that the built environment is multidimensional, with many factors interacting [51]. Further, the findings are embedded in the specific and complex social and geographic context of the Wellington region. This limits the interpretation of scenario modelling with a specific focus on urban design and transport features.

\section{Conclusions}

The findings of this study emphasize the importance of greater context-specificity in the study of environmental factors and physical activity [52-54]. This was evident in the present study, as several factors (earlier related to more general physical activity behaviours, such as population density) were not related to active commuting in the Wellington region. It also indicates that access to, and frequency of, public transport in the neighbourhood can act as a facilitator for a more active lifestyle among its residents. It should be noted though, that environmental changes could have a differential impact on high and low income individuals.

Due to the limitations presented in the Discussion section, results from this forecasting model should be interpreted with caution. However, promoting a more active lifestyle by improving indirect active commuting facilities—as such, promoting the incorporation of transport-related physical activity into a daily routine-remains the key take-home message of this study. An integrated pull towards 
public transport and push from car driving is a promising strategy to significantly increase active commuting, and therefore, in general physical activity.

Supplementary Materials: The following are available online at www.mdpi.com/2071-1050/8/3/242/s1, Table S1: Summary statistics of exposure measures; Table S2: Association between level of income and duration of active commuter trips (in minutes); Table S3: Correlation of land use and transport variables at the level of the home meshblocks; Table S4: Association between home neighbourhood exposures and duration of active commuter trips (in minutes); Figure S1a and S1b: Illustration of land-use and public transport characteristics within traffic zones in the Wellington region.

Acknowledgments: Joreintje Dingena Mackenbach received a Travel grant from the EMGO+ Institute of the VU University Medical Center Amsterdam. The research of the New Zealand Centre for Sustainable Cities is funded by a grant from the Ministry of Business, Innovation and Employment. Funders had no role in the design, conduct, analysis, interpretation or publication of the manuscript. We thank Helen Viggers, Nevil Pearse, Amber Pearson and Associate professor Michael Keall for their advice on data handling and analysis.

Author Contributions: Joreintje Dingena Mackenbach conceived the study design, carried out data analysis and drafted the manuscript. Ed Randal participated in the data collection and analysis. Pengjun Zhao participated in the data collection and analysis and helped conceive the study. Philippa Howden-Chapman helped conceive the study and helped draft the manuscript. All authors read and approved the final manuscript.

Conflicts of Interest: The authors declare no conflict of interest.

\section{Abbreviations}

The following abbreviations are used in this manuscript:

NZHTS New Zealand Household Travel Survey

WILUTE Wellington Integrated Land-Use Transportation and Environment Model

\section{References}

1. Physical Activity Guidelines Advisory Committee. Physical Activity Guidelines Advisory Committee; US Department of Health and Human Services: Washington, DC, USA, 2008.

2. Warburton, D.E.R.; Nicol, C.W.; Bredin, S.S.D. Health benefits of physical activity: The evidence. Can. Med. Assoc. J. 2006, 174, 801-809. [CrossRef] [PubMed]

3. Lee, I.-M.; Shiroma, F.J.; Lobelo, F.; Puska, P.; Blair, S.N.; Katzmarzyk, P.T. Effect of physical inactivity on major non-communicable diseases worldwide: An analysis of burden of disease and life expectancy. Lancet 2012, 380, 219-229. [CrossRef]

4. Lahti, J.; Sabia, S.; Singh-Manoux, A.; Kivimaki, M.; Tatsuse, T.; Yamada, M.; Sekine, M.; Lallukka, T. Leisure time physical activity and subsequent physical and mental health functioning among midlife Finnish, British and Japanese employess: A follow-up study in three occupational cohorts. BMJ Open 2016, 6, e009788. [CrossRef] [PubMed]

5. World Health Organization. Physical Activity; World Health Organization: Geneva, Switzerland, 2015.

6. Pucher, J.; Buehler, R.; Bassett, D.R.; Dannenberg, A.L. Walking and cycling to health: A comparative analysis of city, state, and international data. Am. J. Public Health 2010, 100, 1986-1992. [CrossRef] [PubMed]

7. World Health Organization. Global Recommendations on Physical Activity for Health; World Health Organization: Geneva, Switzerland, 2010.

8. Ministry of Health. The Health of New Zealand Adults 2011/12; Ministry of Health: Wellington, New Zealand, 2012.

9. Statistics New Zealand. Main Means of Travel to Work-2013 Census. Available online: http://www.stats. govt.nz/Census /2013-census/profile-and-summary-reports / quickstats-transport-comms/travel-to-work.aspx (accessed on 3 February 2016).

10. Centraal Bureau voor de Statistiek. Verplaatsingen van en naar het werk naar vervoermiddel (Transport from and to Work by Mode in the Dutch Population) 1985-2007. Available online: http:/ /www.cbs.nl/nl$\mathrm{NL} / \mathrm{menu}$ /themas/verkeer-vervoer/publicaties/artikelen/archief/2008/2008-2539-wm.htm (accessed on 3 February 2016). 
11. McCormack, G.R.; Shiell, A. In search of causality: A systematic review of the relationship between the built environment and physical activity among adults. Int. J. Behav. Nutr. Phys. Act. 2011, 8, 125. [CrossRef] [PubMed]

12. Pucher, J.; Buehler, R. Making cycling irresistible: Lessons from the Netherlands, Denmark and Germany. Transp. Rev. 2008, 28, 495-528. [CrossRef]

13. Nazelle, A.; De Nieuwenhuijsen, M.J.; Antó, J.M.; Brauer, M.; Briggs, D.; Braun-fahrlander, C.; Cavill, N.; Cooper, A.R.; Desqueyroux, H.; Fruin, S.; et al. Improving health through policies that promote active travel: A review of evidence to support integrated health impact assessment. Environ. Int. 2011, 37, 766-777. [CrossRef] [PubMed]

14. Cerin, E.; Leslie, E.; Owen, N.; Frank, L.D. Destinations that matter: Associations with walking for transport. Health Place 2007, 13, 713-724. [CrossRef] [PubMed]

15. Rissel, C.; Curac, N.; Greenaway, M.; Bauman, A. Physical activity associated with public transport us-A review and modelling of potential benefits. Int. J. Environ. Res. Public Health 2012, 9, 2454-2478. [CrossRef] [PubMed]

16. Fraser, S.D.S.; Lock, K. Cycling for transport and public health: A systematic review of the effect of the environment on cycling. Eur. J. Public Health 2010, 21, 738-743. [CrossRef] [PubMed]

17. Witten, K.; Blakely, T.; Bagheri, N.; Badland, H.; Ivory, V.; Pearce, J.; Mavoa, S.; Hinckson, E.; Schofield, G. Neighborhood built environment and transport and leisure physical activity: Findings using objective exposure and outcome measures in New Zealand. Environ. Health Perspect. 2012, 120, 971-977. [CrossRef] [PubMed]

18. Martin, A.; Suhrcke, M.; Ogilvie, D. Financial Incentives to Promote Active Travel. AMEPRE 2012, 43, e45-e57. [CrossRef] [PubMed]

19. Pucher, J.; Dill, J.; Handy, S. Infrastructure, programs, and policies to increase bicycling: An international review. Prev. Med. (Baltim.) 2010, 50, 106-125. [CrossRef] [PubMed]

20. Kerr, J.; Sallis, J.F.; Owen, N.; De Bourdeaudhuij, I.; Cerin, E.; Sugiyama, T.; Reis, R.; Sarmiento, O.; Frömel, K.; Mitás, J.; et al. Advancing Science and Policy Through a Coordinated International Study of Physical Activity and Built Environments: IPEN Adult Methods. J. Phys. Act. Health 2013, 10, 581-601. [PubMed]

21. Badland, H.; Hickey, S.; Bull, F.; Giles-Corti, B. Public transport access and availability in the RESIDE study: Is it taking us where we want to go? J. Transp. Heal. 2014, 1, 45-49. [CrossRef]

22. Wegener, M. Overview of land-use transport models. In Transport Geography and Spatial Systems; Hensher, D.A., Button, K., Eds.; Pergamon/Elsevier Science: Kidlington, UK, 2004; pp. 127-146.

23. Beenackers, M.A.; Kamphuis, C.B.M.; Giskes, K.; Brug, J.; Kunst, A.E.; Burdorf, A.; van Lenthe, F. Socioeconomic inequalities in occupational, leisure-time, and transport related physical activity among European adults: A systematic review. Int. J. Behav. Nutr. Phys. Act. 2012, 9, 116. [CrossRef] [PubMed]

24. De Munter, J.S.; Agyemang, C.; Brewster, L.M.; Stronks, K.; van Valkengoed, I.G. The association of leisure-time physical activity and active commuting with measures of socioeconomic position in a multiethnic population living in the Netherlands: results from the cross-sectional SUNSET study. BMC Public Health 2012, 21, 815. [CrossRef] [PubMed]

25. Adams, J. Prevalence and socio-demographic correlates of "active transport" in the UK: Analysis of the UK time use survey 2005. Prev. Med. (Baltim.) 2010, 50, 199-203. [CrossRef] [PubMed]

26. Goodman, A. Walking, Cycling and Driving to Work in the English and Welsh 2011 Census: Trends, Socio-Economic Patterning and Relevance to Travel Behaviour in General. PLoS ONE 2013, 8, e71790.

27. Cerin, E.; Leslie, E.; Owen, N. Explaining socio-economic status differences in walking for transport: An ecological analysis of individual, social and environmental factors. Soc. Sci. Med. 2009, 68, 1013-1020. [CrossRef] [PubMed]

28. Wellington City Council. Wellington Urban Growth Plan; Wellington City Council: Wellington, New Zealand, 2014.

29. Ministry of Transport. New Zealand Household Travel Survey. Available online: http://www.transport. govt.nz/research/travelsurvey/detailedtravelsurveyinformation/ (accessed on 6 February 2016).

30. Galobardes, B.; Shaw, M.; Lawlor, D.A.; Lynch, J.W.; Smith, G.D. Indicators of socioeconomic position (part 1). J. Epidemiol. Community Health 2006, 60, 7-12. [CrossRef] [PubMed] 
31. Kerr, J.; Emond, J.A.; Badland, H.; Reis, R.; Sarmiento, O.; Carlson, J.; Sallis, J.F.; Cerin, E.; Cain, K.; Conway, T.; et al. Perceived Neighborhood Environmental Attributes Associated with Walking and Cycling for Transport among Adult Residents of 17 Cities in 12 Countries: The IPEN Study. Environ. Health Perspect. 2015. [CrossRef] [PubMed]

32. ESRI. ArcGIS Desktop: Release 10; Enviromental Systems Research Institute: Redlands, CA, USA, 2011.

33. Salmond, C.; Crampton, P.; Atkinson, J. NZDep2006 Index of Deprivation; University of Otago (Department of Public Health): Wellington, New Zealand, 2007.

34. Singer, J.D. Using SAS PROC MIXED to fit multilevel models, hierarchical models, and individual growth models. J. Educ. Behav. Stat. 1998, 24, 323-355. [CrossRef]

35. Ewing, R.; Cervero, R. Travel and the Built Environment. J. Am. Plan. Assoc. 2010, 76, 265-294. [CrossRef]

36. StataCorp. Stata Statistical Software: Release 12; StataCorp LP: College Station, TX, USA, 2011.

37. Zhao, P.; Chapman, R.; Randal, E.; Howden-Chapman, P. Understanding Resilient Urban Futures: A Systemic Modelling Approach. Sustainability 2013, 5, 3202-3223. [CrossRef]

38. Ministry of Transport. How New Zealanders Travel. Trends in New Zealand Household Travel 1989-2008; Ministry of Transport: Wellington, New Zealand, 2009.

39. Mckim, L. The economic geography of active commuting: Regional insights from Wellington, New Zealand. Reg. Stud. Reg. Sci. 2014, 1, 88-95. [CrossRef]

40. Saelens, B.E.; Handy, S.L. Built Environment Correlates of Walking: A Review. Med. Sci. Sport. Exerc. 2008, 40, S550-S556. [CrossRef] [PubMed]

41. Rundle, A.; Diez Roux, A.V.; Free, L.M.; Miller, D.; Neckerman, K.M.; Weiss, C.C. The urban built environment and obesity in New York City: A multilevel analysis. Am. J. Health Promot. 2007, 21, 326-334. [CrossRef] [PubMed]

42. Zhao, Z.; Kaestner, R. Effects of urban sprawl on obesity. J. Health Econ. 2010, 29, 779-787. [CrossRef] [PubMed]

43. Ewing, R.; Schmid, T.; Killingsworth, R.; Zlot, A.; Raudenbush, S. Relationship between urban sprawl and physical activity, obesity, and morbidity. Am. J. Health Promot. 2003, 18, 47-57. [CrossRef] [PubMed]

44. Wener, R.E.; Evans, G.W. A morning stroll: Levels of physical activity in car and mass transit commuting. Environ. Behav. 2007, 39, 62-74. [CrossRef]

45. Besser, L.M.; Dannenberg, A.L. Walking to Public Transit Steps to Help Meet Physical Activity Recommendations. Am. J. Prev. Med. 2010, 29, 273-280. [CrossRef] [PubMed]

46. Feeney, B.P. A review of the impact of parking policy measures on travel demand. Transp. Plan. Technol. 1989, 13, 229-244. [CrossRef]

47. Gillen, D.W. Estimation and Specification of the Effects of Parking Costs on Urban Transport Mode Choice. J. Urban Econ. 1977, 4, 186-199. [CrossRef]

48. Levinson, D. Equity effects of road pricing: A review. Transp. Rev. 2010, 30, 33-57. [CrossRef]

49. Markovich, J.; Lucas, K. The Social and Distributional Impacts of Transport: A Literature Review; University of Oxford: Oxford, UK, 2011.

50. Lyseen, A.K.; Hansen, H.S.; Harder, H.; Jensen, A.S.; Mikkelsen, B.E. Defining neighbourhoods as a measure of exposure to the food environment. Int. J. Environ. Res. Public Health 2015, 12, 8504-8525. [CrossRef] [PubMed]

51. Williams, L.M. Getting to Know the Built Environment as A Complex System; Wellesley Institute: Toronto, ON, Canada, 2013.

52. Owen, N.; Humpel, N.; Leslie, E.; Bauman, A.; Sallis, J.F. Understanding environmental influences on walking; Review and research agenda. Am. J. Prev. Med. 2004, 27, 67-76. [CrossRef] [PubMed]

53. Giles-Corti, B.; Timperio, A.; Bull, F.; Pikora, T. Understanding physical activity environmental correlates: Increased specificity for ecological models. Exerc. Sport Sci. Rev. 2005, 33, 175-181. [CrossRef] [PubMed]

54. Saelens, B.E.; Sallis, J.F.; Black, J.B.; Chen, D. Neighborhood-based differences in physical activity: An environment scale evaluation. Am. J. Public. Health 2003, 93, 1552-1558. [CrossRef] [PubMed]

(C) 2016 by the authors; licensee MDPI, Basel, Switzerland. This article is an open access article distributed under the terms and conditions of the Creative Commons by Attribution (CC-BY) license (http://creativecommons.org/licenses/by/4.0/). 